\title{
Poor Sensitivity of Fecal Gluten Immunogenic Peptides and Serum Antibodies to Detect Duodenal Mucosal Damage in Celiac Disease Monitoring
}

\author{
Emilio J. Laserna-Mendieta 1,2,3,*D, María José Casanova 2,4,5,6, Ángel Arias 2,6,7 (D), Laura Arias-González 1,2 , \\ Pedro Majano ${ }^{2,6}$, Luis Alberto Mate ${ }^{8}$, Carlos Humberto Gordillo-Vélez ${ }^{2,9}$, Mirella Jiménez ${ }^{2,4}$, Teresa Angueira ${ }^{1}$, \\ Emilia Tébar-Romero ${ }^{1}$ (D), María Jesús Carrillo-Ramos ${ }^{1}$, María Ángeles Tejero-Bustos ${ }^{1}$, Javier P. Gisbert ${ }^{2,4,5,6} \mathbb{D}$, \\ Cecilio Santander $2,4,6$ (D) and Alfredo J. Lucendo $1,2,6, * \mathbb{D}$
}

check for updates

Citation: Laserna-Mendieta, E.J.;

Casanova, M.J.; Arias, Á.;

Arias-González, L.; Majano, P.; Mate, L.A.; Gordillo-Vélez, C.H.; Jiménez, M.; Angueira, T.;

Tébar-Romero, E.; et al. Poor Sensitivity of Fecal Gluten Immunogenic Peptides and Serum Antibodies to Detect Duodenal Mucosal Damage in Celiac Disease Monitoring. Nutrients 2021, 13, 98. https://doi.org/10.3390/nu13010098

Received: 30 November 2020 Accepted: 24 December 2020 Published: 30 December 2020

Publisher's Note: MDPI stays neutral with regard to jurisdictional clai$\mathrm{ms}$ in published maps and institutional affiliations.

Copyright: (C) 2020 by the authors. Licensee MDPI, Basel, Switzerland. This article is an open access article distributed under the terms and conditions of the Creative Commons Attribution (CC BY) license (https:// creativecommons.org/licenses/by/ $4.0 /)$
1 Department of Gastroenterology, Hospital General de Tomelloso, 13700 Tomelloso, Spain; laura.arias.gonzalez@gmail.com (L.A.-G.); teresa.angueira@gmail.com (T.A.); emiliatebar@hotmail.com (E.T.-R.); mjcr34@hotmail.com (M.J.C.-R.); angelestejero@hotmail.com (M.Á.T.-B.)

2 Instituto de Investigación Sanitaria Princesa, 28006 Madrid, Spain; angel_arias_arias81@hotmail.com (Á.A.) pmajano@gmail.com (P.M.); cahugove@hotmail.com (C.H.G.-V.)

3 Clinical Laboratory, Hospital Universitario La Princesa, 28006 Madrid, Spain

4 Department of Gastroenterology, Hospital Universitario de La Princesa, Instituto de Investigación Sanitaria Princesa (IIS-IP), 28006 Madrid, Spain; mjcasanova.g@gmail.com (M.J.C.); mirella_altea@hotmail.com (M.J.); javier.p.gisbert@gmail.com (J.P.G.); cecilio.santander@salud.madrid.org (C.S.)

5 Enfermedades Inflamatorias Esófago-Gastro-Intestinales, Universidad Autónoma de Madrid (UAM), 28049 Madrid, Spain

6 Centro de Investigación Biomédica en Red de Enfermedades Hepáticas y Digestivas (CIBEREHD), 28222 Madrid, Spain

7 Research Unit, Hospital General Mancha Centro, 13600 Alcázar de San Juan, Spain

8 Pathology Department, Hospital General Mancha Centro, 13600 Alcázar de San Juan, Spain; lmatmcmar@gmail.com

9 Pathology Department, Hospital Universitario La Princesa, 28006 Madrid, Spain

* Correspondence: ejlaserna@sescam.jccm.es (E.J.L.-M.); ajlucendo@hotmail.com (A.J.L.); Tel.: +34-926-525-800 (ext. 71268) (E.J.L.-M.); +34-926-525-800 (ext. 71137) (A.J.L.)

Abstract: A lifelong gluten-free diet (GFD) is the only current treatment for celiac disease (CD), but strict compliance is complicated. Duodenal biopsies are the "gold standard" method for diagnosing $\mathrm{CD}$, but they are not generally recommended for disease monitoring. We evaluated the sensitivity and specificity of fecal gluten immunogenic peptides (GIPs) to detect duodenal lesions in CD patients on a GFD and compared them with serum anti-tissue transglutaminase (tTG) IgA antibodies. A prospective study was conducted at two tertiary centers in Spain on a consecutive series of adolescents and adults with CD who maintained a long-lasting GFD. Adherence to a GFD and health-related quality of life were scored with validated questionnaires. Mucosal damage graded according to the Marsh-Oberhüber classification (Marsh 1/2/3) was used as the reference standard. Of the 97 patients included, 27 presented duodenal mucosal damage and 70 had normal biopsies (Marsh 0). The sensitivity (33\%) and specificity (81\%) of GIPs were similar to those provided by the two assays used to measure anti-tTG antibodies. Scores in questionnaires showed no association with GIP, but an association between GIPs and patients' self-reported gluten consumption was found ( $p=0.003)$. GIP displayed low sensitivity but acceptable specificity for the detection of mucosal damage in CD.

Keywords: celiac disease; gluten-free diet monitoring; Marsh-Oberhüber type; gluten immunogenic peptides; anti-tissue transglutaminase antibodies; diagnostic accuracy

\section{Introduction}

Celiac disease (CD) is a chronic immune-mediated enteropathy, triggered and maintained by gluten consumption in genetically predisposed individuals, and characterized 
by damage of variable intensity in their duodenal mucosa [1]. A lifelong adherence to a gluten-free diet (GFD) is currently the only therapy for these patients, which usually leads to complete mucosal recovery. However, strict compliance to a GFD can be compromised by unnoticed gluten consumption, cross-contamination, or social pressure when eating out and unspecific or even absent symptomatology after transgressions [2]. As a consequence, $30 \%$ to $60 \%$ of patients with CD are exposed to gluten despite their best efforts [3-5].

Continuous gluten exposure causes permanent damage in the duodenal mucosa of celiac patients and increases the risk of bone and endocrinological diseases [6] or intestinal lymphoma [7]; lack of adherence to a GFD also reduces health-related quality of life (HRQoL) [8]. Monitoring sustained adherence to a GFD in celiac patients is, therefore, essential. This is mainly undertaken by surveying symptoms, administering nutritional questionnaires, and using non-invasive serological markers. The assessment of duodenal biopsies, which is considered the gold standard, is rarely performed during the follow-up of $\mathrm{CD}$ due to its invasiveness, relative risk, and high cost [9]. Persistence of duodenal mucosal lesions is more commonly found in adults compared to children and in those with a shorter time on a GFD $[10,11]$.

There is a general consensus about the limitations of both patient-reported questionnaires and serological tests in detecting gluten transgressions and persistence of mucosal damage during the follow-up of CD [12,13]. Anti-tissue transglutaminase (tTG) and anti-endomysium antibodies are highly sensitive markers for the diagnosis of $\mathrm{CD}$, but a meta-analysis showed their sensitivity in identifying villous atrophy fell below $50 \%$ once patients were on a GFD [14]. Therefore, celiac patients with negative antibody levels during follow-up could have undetected duodenal damage for years.

The detection in urine and fecal samples of gluten immunogenic peptides (GIPs), responsible for most of the immune-toxic reactions mediated by gluten in CD patients [15], has been proposed as being useful to check GFD compliance [16]. A manufacturersponsored study showed that $71 \%$ of the patients with Marsh type $2 / 3$ lesions in duodenal biopsies showed negative serum antibodies, while positive urine GIPs were detected in all of the patients [17]. GIP measurement in stools, where they are present for 2-4 days after gluten ingestion, has been used to monitor adherence to GFD [18-20]. However, to date, no independent studies have evaluated the correlation between GIP detection in feces and changes in the duodenal mucosal histology in a real-life clinical setting.

In this study, our aim was to ascertain the utility of measuring GIPs with a qualitative lateral-flow immunochromatography assay in a single stool sample to detect duodenal mucosal lesions. To that end, we recruited adolescent and adult patients with CD in a clinical setting in two Spanish tertiary hospitals and assessed whether performing fecal GIP during CD monitoring is superior to serum tTG IgA antibodies' measurement, as an index test, in detecting mucosal lesions by comparing them to the clinical reference standard: histopathological analysis of duodenal biopsies. In addition, HRQoL and patient-declared adherence to a GFD were measured to check for relationships between histological and laboratory results.

\section{Subjects and Methods}

\subsection{Study Design and Reporting}

The protocol was designed as a prospective observational study to evaluate the diagnostic accuracy of laboratory tests. The whole manuscript has been redacted to fulfill the essential items for the Standards for Reporting of Diagnostic Accuracy Studies, STARD 2015 [21].

\subsection{Study Population}

A consecutive series of adolescents and adult patients (age $\geq 14$ years) with an established diagnosis of $\mathrm{CD}$, more than one year on a GFD, and who attended either the Gastroenterology out-patient clinic at Hospital General de Tomelloso (HGT, Tomelloso, Spain) or Hospital Universitario de La Princesa (HUP, Madrid, Spain) between May 2018 
and July 2020 were invited to participate in this study. Pregnant women, patients with other concomitant severe diseases, those with wheat allergy, non-celiac gluten sensitivity, and known refractory $C D$ were not invited to participate. No prior calculation of sample size was performed. Recruited patients were given an appointment for an upper endoscopy and instructed to collect a fecal sample the day before the appointment. They were instructed to keep the sample at $4{ }^{\circ} \mathrm{C}$ until it was brought to the hospital.

\subsection{Upper Endoscopy and Duodenal Biopsies}

An esophago-gastro-duodenoscopy (EGD) under sedation with propofol was performed according to clinical practice. As per protocol, five biopsies from the second portion of the duodenum and two more from the duodenal bulb were obtained from each patient to investigate the persistence of mucosal lesions [22]. No reported adverse event occurred in any of the patients during the EGD.

The paraffin-embedded samples were cut, stained with hematoxylin-eosin, and studied under a light microscope by a single expert pathologist, blind to clinical and laboratory data, at each institution. Only representative and carefully orientated mucosal sections were included in the histopathological analysis. Quantification of the intraepithelial lymphocytes was performed through immunohistochemical examinations and using CD3 monoclonal antibodies for doubtful cases (Roche Diagnostics, Penzberg, Germany). The mucosal specimens were graded independently in accordance with the Marsh-Oberhüber classification: infiltration of intraepithelial lymphocytes $>25 \%$ (type 1 ), crypt hyperplasia (type 2), and villous atrophy (type 3) [23,24]. This classification is widely accepted as a reference standard for $\mathrm{CD}$ assessment in clinical practice [22]. Presence of mucosal damage was considered when Marsh types 1, 2 or 3 were reported by the pathologists.

\subsection{Measurement of GIPS}

Patient stool samples were frozen at $-40{ }^{\circ} \mathrm{C}$ as soon as they were delivered to medical staff, before the EGD. For GIP measurement, the samples were defrosted for $4-5 \mathrm{~h}$ and later homogenized. GIP detection was performed for all samples at HGT using iVYCHECK GIP-Stool (Biomedal, Sevilla, Spain) and following the manufacturer instructions. This assay is based on lateral-flow immunochromatography and provides a qualitative result. Interpretation was visually performed after $30 \mathrm{~min}$ of sample pouring. The presence of both green and red lines was considered GIP positive while the presence of only a green band was interpreted as GIP negative. Samples with the appearance of a green line at $30 \mathrm{~min}$ but not at $10 \mathrm{~min}$ were considered weak positives. No indeterminate results (presence of red band in absence of green band) were obtained. The limit of detection of the test was $0.15 \mu \mathrm{g}$ GIP/g of stool, so this cutoff point represents the GIP concentration above which the test was positive.

GIP tests were performed in batches of several samples (normally 4 to 6) without knowing the reference standard results.

\subsection{Measurement of Anti-tTG IgA}

Blood from patients was extracted just before EGD for serum anti-tTG IgA determination. In addition, serum IgA levels were also measured to detect IgA deficiency, which was confirmed when the IgA concentration was lower than $70 \mathrm{mg} / \mathrm{dL}$.

In HGT, anti-tTG IgA was measured with Liaison tTG IgA assay (DiaSorin, Saluggia, Italy) and manufacturer reference values were 0-8 UA/mL (lower limit of detection $0.2 \mathrm{UA} / \mathrm{mL}$ ). Therefore, the test was interpreted as positive for anti-tTG concentrations above $8 \mathrm{UA} / \mathrm{mL}$ in the absence of IgA deficiency.

In HUP, anti-tTG IgA was measured with Quanta Flash IgA tTG assay (Werfen Diagnostics, Barcelona, Spain) and manufacturer reference values were 0-20 UA/mL (lower limit of detection $1.9 \mathrm{UA} / \mathrm{mL}$ ). Consequently, the test was interpreted as positive for anti-tTG concentrations above $20 \mathrm{UA} / \mathrm{mL}$ in the absence of IgA deficiency. 
At both sites, blood samples were processed in the corresponding auto-analyzers the day after the EGD, so the anti-tTG IgA result was completed for each patient before reference standard results were available. No indeterminate results were obtained from any sample, and patients with IgA deficiency were excluded from the final analyses.

\subsection{Gluten-Free-Diet Adherence and HRQoL Questionnaires}

On the same day and just prior to the EGD exam, patients were asked to complete two questionnaires previously adapted and validated linguistically and culturally in Spanish.

HRQoL was assessed using a celiac-specific questionnaire. This is a self-administered questionnaire, with 20 items across four clinically relevant subscales and answered using a Likert scale. The overall score is expressed on a scale of 20 to 100 points, with higher scores indicating better health and lower ones indicating higher stress levels due to CD [25].

The Spanish translation of the Celiac Dietary Adherence Test (CDAT) was used to evaluate adherence to the GFD; this consists of 7 items with a five-point scale for each item (7 to 35 points). Higher scores reflect poor adherence to GFD; with the last item asking about self-conscious gluten ingestion [26].

\subsection{Statistical Analyses}

Mean and standard deviations were reported for continuous variables and proportions for categorical data. The normality of continuous variables was checked using the Kolmogorov-Smirnov test. The Student t-test was employed for normal-distributed variables, while the U-Mann-Whitney test was used when normality was absent. For categorical data, contingency tables were produced and analyzed by chi-square or Fisher exact tests.

Sensitivity, specificity, positive predictive value (PPV), negative predictive value (NPV), and their $95 \%$ confidence intervals $(95 \% \mathrm{CI})$ were calculated for GIP and tTG performance compared to the gold standard, which was the presence of any mucosal damage in the duodenum according to Marsh-Oberhüber classification. The percentage of agreement between methods was also calculated. The Kappa statistic was used for concordance between GIPs and mucosal lesions, as both were interpreted qualitatively. In addition, quantitative tTG values were employed to calculate the area under the receiver operating characteristic curve (AUC-ROC) and to estimate the optimal cutoff value by using the Youden index.

All statistical analyses were carried out using PASW version 18.0 (SPSS Inc., Chicago, IL, USA), GraphPad Prism version 5.0 (GraphPad Software, San Diego, CA, USA), and Epidat v4.2 (Servicio Gallego de Salud, Santiago de Compostela, Spain). Statistical significance was considered when $p<0.05$.

\section{Results}

\subsection{Demographic and Clinical Characteristics of Patients}

Ninety-eight patients underwent EGD and provided fecal and serum samples (Figure 1). One patient from HGT was excluded due to a problem with biopsy sample processing at the Pathology Department. Table 1 shows the characteristics of the 97 patients finally included in the study. A female:male ratio of 3:1 was found, in agreement with the reported $\mathrm{CD}$ sex distribution. Mean age was close to 40 years old, and patients were on a GFD for a mean of 105 months, that is, almost 9 years. Most patients (62\%) presented villous atrophy (Marsh 3) at the point of diagnosis. 
Table 1. Demographic and clinical characteristics of patients included in the study and statistical comparison between both recruiting hospitals.

\begin{tabular}{|c|c|c|c|c|c|}
\hline & & Total & HGT & HUP & $p$ \\
\hline \multicolumn{2}{|l|}{ Patients } & 97 & 64 & 33 & \\
\hline \multirow{2}{*}{ Sex } & Female & $75(77.3 \%)$ & $48(75.0 \%)$ & $27(81.8 \%)$ & \multirow{2}{*}{0.477} \\
\hline & Male & $22(22.7 \%)$ & $16(25.0 \%)$ & $6(18.2 \%)$ & \\
\hline \multicolumn{2}{|l|}{ Age (years) } & $39.7 \pm 18.0(14-77)$ & $38.0 \pm 19.2(14-75)$ & $43.2 \pm 15.1(20-77)$ & 0.180 \\
\hline \multicolumn{2}{|c|}{ Age (years) at diagnosis } & $31.0 \pm 19.9(0-72)$ & $29.1 \pm 21.1(1-68)$ & $34.6 \pm 17.1(0-72)$ & 0.168 \\
\hline \multicolumn{2}{|l|}{ Months in GFD } & $104.9 \pm 89.7(12-362)$ & $106.3 \pm 84.4(12-362)$ & $102.1 \pm 100.6(12-318)$ & 0.826 \\
\hline \multirow{4}{*}{ Marsh type at diagnosis (\%) } & Marsh 3 & $60(61.9 \%)$ & $38(59.4 \%)$ & $22(66.7 \%)$ & \multirow{4}{*}{0.313} \\
\hline & Marsh 2 & $9(9.3 \%)$ & $8(12.5 \%)$ & $1(3.0 \%)$ & \\
\hline & Marsh 1 & $11(11.3 \%)$ & $7(10.9 \%)$ & $4(12.1 \%)$ & \\
\hline & Unknown & $17(17.5 \%)$ & $11(17.2 \%)$ & $6(18.2 \%)$ & \\
\hline \multirow{4}{*}{ Marsh type currently (\%) ${ }^{a}$} & Marsh 3 & $3(3.1 \%)$ & 0 & $3(9.1 \%)$ & \multirow{4}{*}{0.695} \\
\hline & Marsh 2 & $3(3.1 \%)$ & $3(4.7 \%)$ & 0 & \\
\hline & Marsh 1 & $21(21.6 \%)$ & $14(21.9 \%)$ & $7(21.2 \%)$ & \\
\hline & Marsh 0 & $70(72.2 \%)$ & $47(73.4 \%)$ & $23(69.7 \%)$ & \\
\hline \multicolumn{2}{|c|}{ Positive fecal GIPs (\%) $b$} & $22(22.7 \%)[54.5 \%]$ & $15(23.4 \%)[53.3 \%]$ & $7(21.2 \%)[57.1 \%]$ & 0.804 \\
\hline \multicolumn{2}{|c|}{ Positive serum anti-tTG IgA (\%) ${ }^{c}$} & $11(11.8 \%)$ & $2(3.3 \%)$ & $9(28.1 \%)$ & 0.001 \\
\hline \multicolumn{2}{|c|}{ Health-related quality of life score ${ }^{d}$} & $71.6 \pm 12.1(39-96)$ & $71.0 \pm 12.7(39-96)$ & $72.7 \pm 10.9(40-89)$ & 0.520 \\
\hline \multicolumn{2}{|l|}{ CDAT score ${ }^{\mathrm{e}}$} & $12.2 \pm 4.0(7-27)$ & $12.2 \pm 3.9(7-24)$ & $12.1 \pm 4.3(7-27)$ & 0.910 \\
\hline \multicolumn{2}{|c|}{ Self-reported gluten consumption $(\%)^{\mathrm{f}}$} & $17(17.5 \%)$ & $15(23.4 \%)$ & $2(6.1 \%)$ & 0.033 \\
\hline
\end{tabular}

HGT: Hospital General de Tomelloso; HUP: Hospital Universitario de La Princesa; GFD: gluten-free diet; GIPs: gluten immunogenic peptides; tTG IgA: tissue transglutaminase immunoglobulin A; CDAT: Celiac Dietary Adherence Test. Significant differences between patients recruited in different hospitals are highlighted in bold. ${ }^{a}$ Marsh 2 and Marsh 3 were grouped together for the statistical comparison between hospitals. ${ }^{b}$ The percentage of total positives considered as weak positives (GIP band visible at $30 \mathrm{~min}$ but not at $10 \mathrm{~min}$ ) is showed in brackets. ${ }^{\mathrm{c}}$ Three patients from HGT and one patient from HUP are not included as they presented IgA deficiency. ${ }^{\mathrm{d}}$ Higher scores indicate better quality of life. ${ }^{\mathrm{e}}$ Higher scores indicate worse adherence to a GFD. ${ }^{\mathrm{f}}$ Patient self-reported gluten consumption in the last month based on the response to the last question of adherence to GFD questionnaire.

Characteristics of patients recruited at the two hospitals were similar (Table 1), with no differences detected for most variables. However, serum anti-tTG was most frequently positive at HUP ( $p=0.001)$, and more patients at HGT declared self-reported gluten consumption in the last month $(p=0.033)$.

No differences were observed in the age of the patients with complete mucosal recovery (Marsh type 0) compared to those with Marsh 1/2/3 (mean and SD being $38.9 \pm 18.0$ vs. $41.9 \pm 18.1$ years; $p=0.466$ ). However, complete mucosal recovery was associated with longer duration of the GFD rather than presence of any mucosal damage (114.9 $\pm 96.7 \mathrm{vs}$. $78.9 \pm 62.9$ months; $p=0.035$ ). 


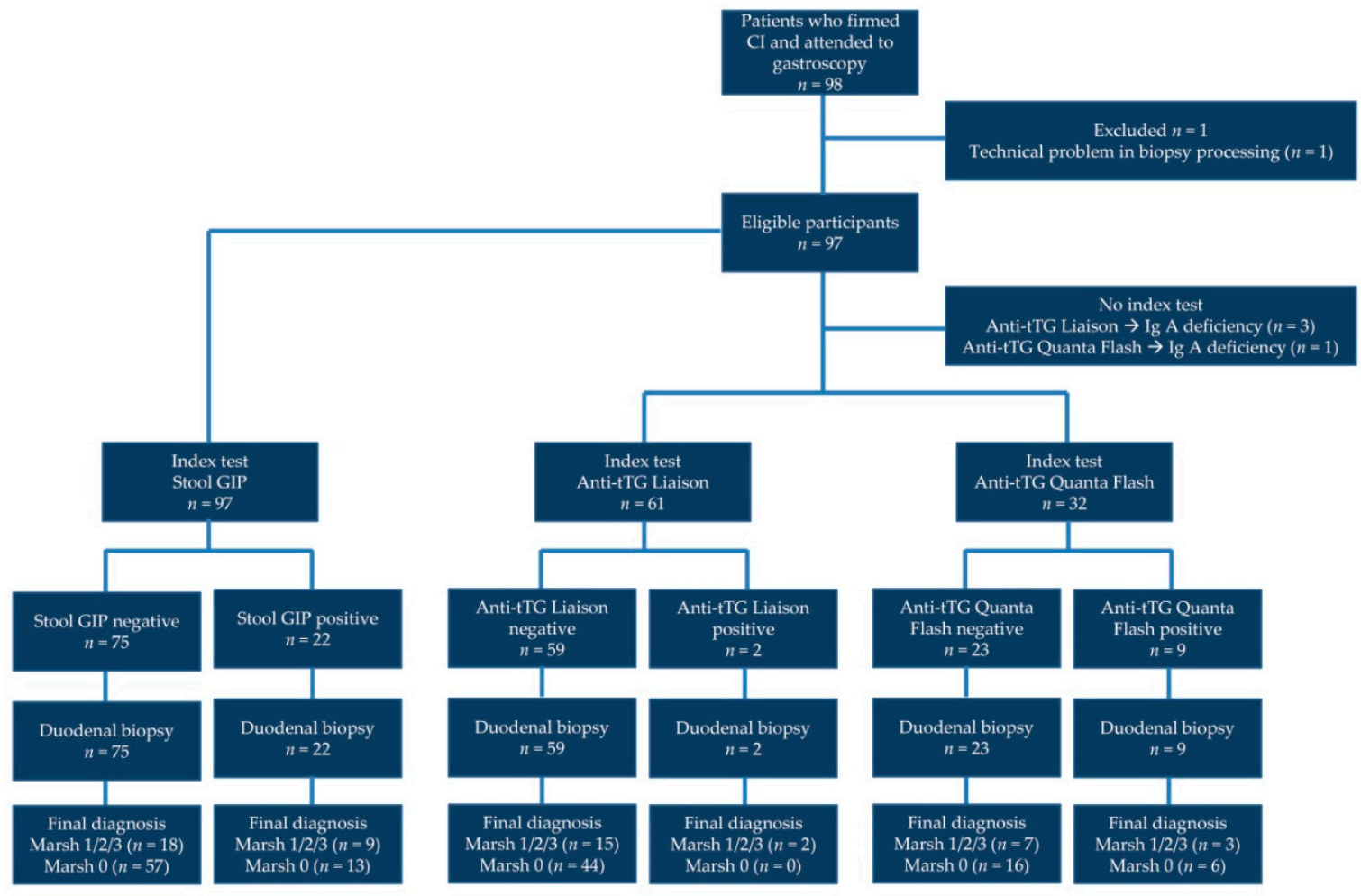

Figure 1. Flowchart of participants through the study.

\subsection{Performance of GIP Detection in Stool Samples to Identify Mucosal Damage}

GIPs were detected in $22.7 \%$ of the patients, with no differences between recruiting hospitals and with more than half of the samples (55\%) being weak positives. No differences in sex, age, length on a GFD, and Marsh type at diagnosis were observed between patients with positive and negative GIP results.

Compared to duodenal histology as the gold standard, the sensitivity and specificity of GIPs to detect any mucosal damage were 33.3\% (CI 95\%, 18.6-52.2\%) and $81.4 \%$ (CI 95\%, 70.8-88.8\%), respectively (Table 2). PPV and NPV were $40.9 \%$ (CI 95\%, 23.3-61.3\%) and $76 \%$ (CI 95\%, 65.2-84.2\%), respectively, with an agreement of $68 \%$ and a kappa of 0.157 (CI $95 \%,-0.053$ to 0.366 ). GIPs were undetected in 4 of the 6 patients with the most severe mucosal damage (Marsh type 2/3) (Table 3).

Table 2. Diagnostic performance of presence of gluten immunogenic peptides (GIPs) in stool and serum anti-tissue transglutaminase (tTG) IgA assays to detect mucosal damage in duodenal biopsies.

\begin{tabular}{|c|c|c|c|c|c|c|c|c|c|}
\hline & Marsh0 & Marsh1/2/3 & Total & AUC & AG & SE & SP & PPV & NPV \\
\hline \multicolumn{10}{|c|}{ GIP (iVYCHECK, Biomedal) } \\
\hline Positive (>0.15 $\mu \mathrm{g} / \mathrm{g})$ & 13 & 9 & 22 & \multirow{2}{*}{-} & \multirow{2}{*}{$68.0 \%$} & \multirow{2}{*}{$33.3 \%$} & \multirow{2}{*}{$81.4 \%$} & \multirow{2}{*}{$40.9 \%$} & \multirow{2}{*}{$76.0 \%$} \\
\hline Negative $(<0.15 \mu \mathrm{g} / \mathrm{g})$ & 57 & 18 & 75 & & & & & & \\
\hline \multicolumn{10}{|c|}{ Anti-tTG IgA (Liaison, Diasorin) } \\
\hline Positive (>8 UA/mL) & 0 & 2 & 2 & \multirow{2}{*}{0.549} & \multirow{2}{*}{$75.4 \%$} & \multirow{2}{*}{$11.8 \%$} & \multirow{2}{*}{$100 \%$} & \multirow{2}{*}{$100 \%$} & \multirow{2}{*}{$74.6 \%$} \\
\hline Negative (<8 UA/mL) & 44 & 15 & 59 & & & & & & \\
\hline \multicolumn{10}{|c|}{ Anti-tTG IgA (Quanta Flash, Werfen) } \\
\hline Positive (>20 UA/mL) & 6 & 3 & 9 & \multirow{2}{*}{0.564} & \multirow{2}{*}{$59.4 \%$} & \multirow{2}{*}{$30.0 \%$} & \multirow{2}{*}{$72.7 \%$} & \multirow{2}{*}{$33.3 \%$} & \multirow{2}{*}{$69.6 \%$} \\
\hline Negative $(<20 \mathrm{UA} / \mathrm{mL})$ & 16 & 7 & 23 & & & & & & \\
\hline
\end{tabular}

AUC: area under the receiver operating characteristic curve; AG: agreement; SE: sensitivity; SP: specificity; PPV: positive predictive value; NPV: negative predictive value. 
Table 3. Demographic data, clinical characteristics, and laboratory results for patients with Marsh type 2/3 in the duodenal biopsy.

\begin{tabular}{|c|c|c|c|c|c|c|c|c|c|c|c|}
\hline Biopsy & Centre & Sex & $\begin{array}{c}\text { Age } \\
(\mathrm{y})\end{array}$ & $\begin{array}{c}\text { GFD } \\
\text { Duration (m) }\end{array}$ & $\begin{array}{c}\text { Marsh } \\
\text { (dx) }\end{array}$ & GIPs & $\begin{array}{c}\text { Anti-tTG IgA } \\
\text { (UA/mL) }\end{array}$ & $\begin{array}{c}\operatorname{IgA} \\
(\mathrm{mg} / \mathrm{dL})\end{array}$ & $\begin{array}{l}\text { HRQoL } \\
\text { Score }\end{array}$ & $\begin{array}{l}\text { CDAT } \\
\text { Score }\end{array}$ & $\begin{array}{l}\text { Gluten } \\
\text { Intake }\end{array}$ \\
\hline \multirow{3}{*}{ Marsh 2} & \multirow{3}{*}{ HGT } & \multirow{2}{*}{ Female } & 18 & 194 & \multirow{3}{*}{ Marsh 3} & $\mathrm{Neg}$ & 2.0 & 305 & 80 & 17 & \multirow{3}{*}{ Yes } \\
\hline & & & 16 & 38 & & \multirow{2}{*}{ Pos } & 1.6 & 205 & 64 & 11 & \\
\hline & & Male & 19 & 77 & & & 14.2 & 329 & 58 & 17 & \\
\hline \multirow{3}{*}{ Marsh 3} & \multirow{3}{*}{ HUP } & \multirow{3}{*}{ Female } & 63 & 41 & \multirow{2}{*}{ Marsh 3} & \multirow{3}{*}{ Neg } & 169.9 & 258 & 62 & 19 & \multirow{3}{*}{ No } \\
\hline & & & 39 & 56 & & & 4.1 & 212 & 86 & 9 & \\
\hline & & & 26 & 302 & Unknown & & $<1.9$ & 172 & 85 & 14 & \\
\hline
\end{tabular}

HGT: Hospital General Tomelloso; HUP: Hospital Universitario de La Princesa; y: years; dx: when celiac disease was diagnosed. GFD: gluten-free diet; m: months; GIPs: gluten immunogenic peptides in stool; Neg: negative; Pos: positive; tTG IgA: tissue transglutaminase immunoglobulin A; HRQoL: health-related quality of life; CDAT: Celiac Dietary Adherence Test. Gluten intake was based on self-reported gluten consumption in the last question of the adherence to gluten-free diet questionnaire.

\subsection{Performance of Serum Anti-tTG IgA Antibodies to Detect Mucosal Damage}

Anti-tTG IgA assays were different in the two recruiting hospitals, resulting in different concentrations and positivity rates. Therefore, both assays were analyzed separately.

Liaison anti-tTG assay showed no significant association with Marsh type $(p=0.074)$, and the sensitivity and specificity to detect any mucosal lesion were $11.8 \%$ (CI 95\%, $3.3-34.3 \%$ ) and $100 \%$ (CI 95\%, 92-100\%), respectively (Table 2). The only two patients with tTG concentration above the cutoff value $(8 \mathrm{UA} / \mathrm{mL})$ presented mucosal lesions, thus resulting in high specificity. The agreement was $75.4 \%$, with a PPV and NPV of $100 \%$ (CI 95\%, 34.2-100\%) and 74.6\% (CI 95\%, 62.2-83.9\%), respectively. The AUC-ROC was 0.549 (CI 95\%, 0.380-0.718) (Supplementary Materials Figure S1), with an optimized cutoff concentration of $0.85 \mathrm{UA} / \mathrm{mL}$, which, however, displayed limited sensitivity $(64.7 \%)$ and specificity $(50 \%)$.

Likewise, poor sensitivity $(30 \%$, CI $95 \%, 6.7-65.3 \%)$, moderate specificity $(72.7 \%$, CI 95\%, 49.8-89.3\%), and no association with Marsh type ( $p=1.0)$ was observed for the Quanta Flash anti-tTG assay (Table 2). Only one out of three patients with Marsh 3 biopsies displayed tTG levels above the cutoff $(20 \mathrm{UA} / \mathrm{mL})$ (Table 3$)$. The agreement was lower than for the Liaison assay $(59.4 \%)$, providing also a lower PPV $(33.3 \%$, CI 95\%, 13.5-61.6\%) and NPV (69.6\%, CI 95\%, 58.6-78.7\%). The AUC-ROC was similar to that calculated for the Liaison anti-tTG assay $(0.564$, CI 95\%, 0.348-0.780) (Supplementary Materials Figure S1), with equally limited performance of the optimized cut-off concentration $(4.0 \mathrm{UA} / \mathrm{mL}$, sensitivity $=80 \%$ and specificity $=40.9 \%$ ).

\subsection{Association between Serum Antibodies and GIP Results}

No differences were detected for quantitative anti-tTG serum values between GIPpositive and GIP-negative patients for any of the anti-tTG assays ( $p=0.884$ for Liaison assay and $p=0.755$ for Quanta Flash assay) (Supplementary Materials Figure S2).

If serum anti-tTG results were interpreted as positive or negative according to the manufacturers' recommended cutoff, a close-to-significance association was found between Liaison anti-tTG assay and stool GIPs $(p=0.050)$, as GIPs were detected in the two patients with positive tTG. Conversely, no relationship was observed between Quanta Flash antitTG assay and GIP detection $(p=1.0)$. 
3.5. Patients' Scores from Questionnaires and Relationship with Demographics, Mucosal Damage, and Laboratory Markers

HRQoL and adherence to GFD (CDAT score) inversely correlated (Pearson's $\mathrm{r}=-0.099 \pm 0.032 ; p=0.003)$ in the sense that a poorer QoL level was associated with a lower adherence to GFD (Supplementary Materials Figure S3).

However, no significant association was observed between HRQoL and CDAT scores when groups were compared for the following variables: age group (14-25 years, 26-55 years, $>55$ years), sex, length on a GFD (12-36 months, 37-120 months, $>120$ months), presence of mucosal damage (Marsh 0 vs. Marsh 1/2/3), and GIP detection. The only association found was patients with positive anti-tTG recruited at HUP showing worse adherence to a GFD (higher CDAT scores) than those with negative ones (14.6 \pm 5.8 vs. $11.1 \pm 3.2 ; p=0.038$.

An association between patient self-reported gluten consumption in the previous month (last question of CDAT questionnaire) and GIP detection was found ( $p=0.003$ ). GIPs were more frequently detected in patients who were aware of any gluten consumption in the last month $(52.9 \%)$ than in those who believed that they had not ingested gluten at all $(16.3 \%)$ (Table 4$)$. This also showed that almost $60 \%$ of patients with positive GIPs were not aware of gluten transgressions.

Table 4. Relationship between detection of gluten immunogenic peptides (GIPs) in stool and patient self-reported gluten consumption in the last month before gastroscopy was performed.

\begin{tabular}{cccc}
\hline & GIP Negative & GIP Positive & Total \\
\hline Gluten consumption & $8(47.1 \%)$ & $9(52.9 \%)$ & 17 \\
\hline No gluten consumption & $67(83.7 \%)$ & $13(16.3 \%)$ & 80 \\
\hline & 75 & 22 & 97 \\
\hline
\end{tabular}

\section{Discussion}

Patients with CD should be monitored to ensure the achievement of positive health outcomes and an appropriate reversion of the mucosal damage caused by gluten. However, monitoring strict compliance of a GFD is controversial in CD management [27]. Although there are several options to evaluate this compliance (presence of symptoms, HRQoL questionnaires, self-reported adherence to a GFD, nutritional counseling, dietary reports, serological assays, and endoscopy with duodenal biopsies), there is no consensus on a suitable methodology and frequency of follow-up in practice guidelines $[9,28]$. In our study, we have assessed the diagnostic accuracy of stool GIPs measured with a qualitative assay to detect mucosal damage in CD patients on a long-term GFD by comparing GIP results with the reference standard method. To our knowledge, this is the first study without GIP manufacturer funding addressing the capability of stool GIPs to detect mucosal damage during monitoring of $\mathrm{CD}$ patients in a real-life clinical setting. According to our results, GIPs had similar sensitivity and specificity to serum anti-tTG IgA for detecting any mucosal damage (Marsh type $1 / 2 / 3$ ), with $22.7 \%$ of patients having gluten transgressions according to single stool GIP detection.

Persistence of mucosal damage is associated with non-responsive CD, which is mostly caused by gluten exposure and rarely ( $1-3 \%$ of patients) by refractory CD [29]. However, current consensus does not recommend endoscopy for routine monitoring of $\mathrm{CD}$, only for complicated cases with persisting symptoms and laboratory-proved deficiencies in micronutrients [9]. Therefore, it is not rare that asymptomatic patients with negative serology have no second endoscopy after $\mathrm{CD}$ diagnosis for years, thus missing possible mucosal lesions [13]. Although recognized as the reference standard method, the specific role of endoscopic surveillance in CD follow-up still needs to be defined [27,30].

Severe mucosal damage (Marsh type 2/3) was found in $6.2 \%$ of our cohort, less than expected according to some previous publications [3-5,31], but in agreement with other studies reporting ratios of $4-6 \%$ after a long-term GFD [32,33]. Patients with mild 
mucosal damage (Marsh 1 or intraepithelial lymphocytosis) represented $21.6 \%$ of our cohort. We assumed that this was caused by persistent CD activity, although mild mucosal damage could be present in other conditions, such as Helicobacter pylori infection, parasitic infections (mainly, Giardia lamblia), small intestinal bacterial overgrowth, lymphocytic colitis, food allergies, or non-steroidal anti-inflammatory treatment [1]. Marsh 1 lesions are present in some CD patients who strictly adhere to a GFD [32] and even persist after GFD optimization [34], so the clinical significance and long-term impact of prolonged duodenal intraepithelial lymphocytosis needs to be investigated further.

As expected, serum anti-tTG IgA assays from different manufacturers varied in numerical values and positivity rates [35]. Despite serum anti-tTG usually falling below the positive threshold one-year after setting up a GFD [36], serology shows low sensitivity for detecting mucosal damage beyond CD diagnosis [14]. Therefore, negative serology does not necessarily indicate mucosal healing. Some alternatives were proposed to improve anti-tTG performance, including the use of undetectable levels as a marker of damage absence [31], employment of reference change values [37], or defining "compliance" in addition to "diagnostic" cutoffs [38]. Regarding the latter, optimized cutoff points according to the Youden index still showed poor diagnostic accuracy in the anti-tTG assays tested, with increases in sensitivity balanced by great decreases in specificity. In our study, the main advantage of Liaison anti-tTG assay was the absence of false positives, as the two patients with positive concentrations had mucosal damage, while positive results in Quanta Flash assay were associated with lower adherence to a GFD measured by the CDAT questionnaire. In contrast, no association was observed between serum anti-tTG IgA concentrations and GIP results as also reported in previous studies [20,39], although others did find agreement between the two tests [40].

A single GIP determination displayed positive results in 22 patients $(22.7 \%)$ and was associated with self-reported gluten consumption. Initial studies assessing urine or stool GIPs provided higher rates of $29.8 \%$ [16] and $46.5 \%$ [17], with positivity increasing further to between $58 \%$ to $89 \%$ when several samples were taken from the same patient over a period [20,39]. In these latest two studies, an increased span of testing, however, led to detecting patients with positive GIPs but no duodenal damage. In our cohort, GIPs were also detected in 13 patients $(13.4 \%$ ) with no mucosal damage (Marsh type 0 ), with 5 of them reporting gluten consumption the month before EGD. A potential tolerance of small amounts of gluten [41] or delay in appearance of mucosal damage could explain this finding, which deserves further investigation. Anyway, although frequency and number of determinations for stool GIP testing have not been established for clinical routine, our results and others from previous publications indicate that the more tests performed, the more patients without mucosal damage will have positive GIPs, which could result in unnecessary increases in costs of CD follow-up.

It should be noted that stool GIPs reflect gluten consumption 2-4 days before the sample is provided, so its use as a surrogate marker for mucosal damage, as suggested in some manufacturer-funded studies, needs to be evaluated carefully. Manufacturer-funded research assessing this issue showed good agreement (80-100\%) between persistence of villous atrophy (Marsh types $2 / 3$ ) and detectable GIPs in either urine $[17,39]$ or both stool and urine [19]. However, our study found negative GIPs in 4 out of 6 patients with Marsh type $2 / 3$ using a single determination in stool, overall providing remarkably low sensitivity (33.3\%) and PPV (40.9\%). Therefore, it would be advisable to combine GIP with other tools. A recent study suggested combining fecal GIPs with a CDAT questionnaire as the best option for monitoring dietary compliance in celiac patients [42].

Among the limitations of our study, the low number of patients with villous atrophy prevented us from specific analyses for this group of patients. The long period of our cohort on a GFD was the likely cause of this, as reported in other cohorts with long lasting adherence. Marsh type 1 was interpreted as being caused by CD, but other potential causes of intraepithelial lymphocytosis should also be acknowledged. Knowing that the effectiveness of the diet was going to be evaluated could have led to better adherence by 
our patients, which is an intrinsic problem of GIP testing. Finally, patients with refractory $\mathrm{CD}$ were not included, nevertheless the potential impact of this rare condition on our results would be negligible given its extremely low prevalence.

\section{Conclusions}

To conclude, stool GIP testing could be useful in certain CD patients to identify gluten transgression leading to persistent mucosal damage, but its sensitivity and specificity in detecting histopathological lesions for a single measurement was not superior to that observed for serum anti-tTG IgA. Finding non-invasive surrogate biomarkers of persistent mucosal damage in $\mathrm{CD}$ is still a requirement, and the employment of different tools for $\mathrm{CD}$ monitoring, depending on the particular clinical situation of each patient, would be the most advisable approach.

Supplementary Materials: The following are available online at https://www.mdpi.com/2072 $-6643 / 13 / 1 / 98 / s 1$, Figure S1: Receiver operating characteristic (ROC) curve for the anti-tissue transglutaminase IgA assays evaluated in the study: Liaison (red) and Quanta Flash (blue); Figure S2: Quantitative results for the anti-tissue transglutaminase (tTG) IgA assays, Liaison and Quanta Flash, when patients were classified according to the result of detection of gluten immunogenic peptides in stool; Figure S3: Correlation between scores obtained in health-related quality of life (HRQoL) and Celiac Dietary Adherence Test (CDAT) questionnaires.

Author Contributions: Conceptualization and methodology, E.J.L.-M., Á.A. and A.J.L.; patient recruitment and endoscopies, M.J.C., M.J., J.P.G., C.S., T.A., E.T.-R., M.J.C.-R., M.Á.T.-B. and A.J.L.; sample processing, E.J.L.-M., L.A.-G. and P.M.; biopsy interpretation, L.A.M. and C.H.G.-V.; data collection, E.J.L.-M. and M.J.C.; data analysis, E.J.L.-M. and Á.A.; writing—original draft preparation, E.J.L.-M.; writing—review and editing, A.J.L. All authors have read and agreed to the published version of the manuscript.

Funding: This research was funded by a grant from Asociación Castellana de Aparato Digestivo (year 2018) to A.J.L.

Institutional Review Board Statement: The study was conducted according to the guidelines of the Declaration of Helsinki, and approved by the Ethics Committee of Hospital General Mancha Centro (protocol code 49-B, approved on 27 June 2018).

Informed Consent Statement: All patients signed the informed consent to participate in the study, and parents signed on behalf of adolescents between 14 and 16 years old.

Data Availability Statement: The data presented in this study are available on request from the corresponding author. The data are not publicly available due to protection of patients' confidential data.

Acknowledgments: We thank the nurses and medical staff in the Department of Gastroenterology of HGT and HUP for their support. We are grateful to Melanie Radcliff for English language revision. E.J.L.-M. is a recipient of a Juan Rodes grant (JR19/00005) from Instituto de Salud Carlos III, which is partly funded by the European Social Fund (period 2014-2020).

Conflicts of Interest: The authors declare no conflict of interest. The funders had no role in the design of the study; in the collection, analyses, or interpretation of data; in the writing of the manuscript; or in the decision to publish the results.

\section{References}

1. Caio, G.; Volta, U.; Sapone, A.; Leffler, D.A.; De Giorgio, R.; Catassi, C.; Fasano, A. Celiac disease: A comprehensive current review. BMC Med. 2019, 17, 142. [CrossRef] [PubMed]

2. Silvester, J.A.; Graff, L.A.; Rigaux, L.; Walker, J.R.; Duerksen, D.R. Symptomatic suspected gluten exposure is common among patients with coeliac disease on a gluten-free diet. Aliment. Pharmacol. Ther. 2016, 44, 612-619. [CrossRef] [PubMed]

3. Lanzini, A.; Lanzarotto, F.; Villanacci, V.; Mora, A.; Bertolazzi, S.; Turini, D.; Carella, G.; Malagoli, A.; Ferrante, G.; Cesana, B.M.; et al. Complete recovery of intestinal mucosa occurs very rarely in adult coeliac patients despite adherence to gluten-free diet. Aliment. Pharmacol. Ther. 2009, 29, 1299-1308. [CrossRef] [PubMed]

4. Lebwohl, B.; Granath, F.; Ekbom, A.; Montgomery, S.M.; Murray, J.A.; Rubio-Tapia, A.; Green, P.H.R.; Ludvigsson, J.F. Mucosal healing and mortality in coeliac disease. Aliment. Pharmacol. Ther. 2013, 37, 332-339. [CrossRef] 
5. Galli, G.; Esposito, G.; Lahner, E.; Pilozzi, E.; Corleto, V.D.; Di Giulio, E.; Aloe Spiriti, M.A.; Annibale, B. Histological recovery and gluten-free diet adherence: A prospective 1-year follow-up study of adult patients with coeliac disease. Aliment. Pharmacol. Ther. 2014, 40, 639-647. [CrossRef]

6. $\quad$ Lebwohl, B.; Michaëlsson, K.; Green, P.H.R.; Ludvigsson, J.F. Persistent mucosal damage and risk of fracture in celiac disease. J. Clin. Endocrinol. Metab. 2014, 99, 609-616. [CrossRef]

7. Lebwohl, B.; Granath, F.; Ekbom, A.; Smedby, K.E.; Murray, J.A.; Neugut, A.I.; Green, P.H.R.; Ludvigsson, J.F. Mucosal healing and risk for lymphoproliferative malignancy in celiac disease: A population-based cohort study. Ann. Intern. Med. 2013, 159, 169-175. [CrossRef]

8. Nachman, F.; del Campo, M.P.; González, A.; Corzo, L.; Vázquez, H.; Sfoggia, C.; Smecuol, E.; Pinto Sanchez, M.I.; Niveloni, S.; Sugai, E. Long-Term deterioration of quality of life in adult patients with celiac disease is associated with treatment noncompliance. Dig. Liver Dis. 2010, 42, 685-691. [CrossRef]

9. Rubio-Tapia, A.; Hill, I.D.; Kelly, C.P.; Calderwood, A.H.; Murray, J.A. ACG clinical guidelines: Diagnosis and management of celiac disease. Am. J. Gastroenterol. 2013, 108, 656-676. [CrossRef]

10. Pietzak, M.M. Follow-Up of patients with celiac disease: Achieving compliance with treatment. Gastroenterology 2005, 128, S135-S141. [CrossRef]

11. Rubio-Tapia, A.; Rahim, M.W.; See, J.A.; Lahr, B.D.; Wu, T.-T.; Murray, J.A. Mucosal recovery and mortality in adults with celiac disease after treatment with a gluten-free diet. Am. J. Gastroenterol. 2010, 105, 1412-1420. [CrossRef] [PubMed]

12. Kaukinen, K.; Peräaho, M.; Lindfors, K.; Partanen, J.; Woolley, N.; Pikkarainen, P.; Karvonen, A.-L.; Laasanen, T.; Sievanen, H.; Maki, M.; et al. Persistent small bowel mucosal villous atrophy without symptoms in coeliac disease. Aliment. Pharmacol. Ther. 2007, 25, 1237-1245. [CrossRef]

13. Sharkey, L.M.; Corbett, G.; Currie, E.; Lee, J.; Sweeney, N.; Woodward, J.M. Optimising delivery of care in coeliac diseaseComparison of the benefits of repeat biopsy and serological follow-up. Aliment. Pharmacol. Ther. 2013, 38, 1278-1291. [CrossRef]

14. Silvester, J.A.; Kurada, S.; Szwajcer, A.; Kelly, C.P.; Leffler, D.A.; Duerksen, D.R. Tests for Serum Transglutaminase and Endomysial Antibodies Do Not Detect Most Patients with Celiac Disease and Persistent Villous Atrophy on Gluten-free Diets: A Meta-Analysis. Gastroenterology 2017, 153, 689-701. [CrossRef] [PubMed]

15. Morón, B.; Cebolla, A.; Manyani, H.; Alvarez-Maqueda, M.; Megías, M.; Thomas, M.D.C.; Carlos Lopez, M.; Sousa, C. Sensitive detection of cereal fractions that are toxic to celiac disease patients by using monoclonal antibodies to a main immunogenic wheat peptide. Am. J. Clin. Nutr. 2008, 87, 405-414. [CrossRef] [PubMed]

16. Comino, I.; Real, A.; Vivas, S.; Síglez, M.Á.; Caminero, A.; Nistal, E.; Casqueiro, J.; Rodriguez-Herrera, A.; Cebolla, A.; Sousa, C. Monitoring of gluten-free diet compliance in celiac patients by assessment of gliadin 33-mer equivalent epitopes in feces. Am. J. Clin. Nutr. 2012, 95, 670-677. [CrossRef] [PubMed]

17. De Loudres Moreno, M.; Cebolla, Á.; Muñoz-Suano, A.; Carrillo-Carrion, C.; Comino, I.; Pizarro, Á.; Leon, F.; Rodriguez-Herrera, A.; Sousa, C. Detection of gluten immunogenic peptides in the urine of patients with coeliac disease reveals transgressions in the gluten-free diet and incomplete mucosal healing. Gut 2017, 66, 250-257. [CrossRef]

18. Syage, J.A.; Kelly, C.P.; Dickason, M.A.; Ramirez, A.C.; Leon, F.; Dominguez, R.; Sealey-Voyksner, J.A. Determination of gluten consumption in celiac disease patients on a gluten-free diet. Am. J. Clin. Nutr. 2018, 107, 201-207. [CrossRef]

19. Silvester, J.A.; Comino, I.; Kelly, C.P.; Sousa, C.; Duerksen, D.R. DOGGIE BAG Study Group. Most Patients with Celiac Disease on Gluten-Free Diets Consume Measurable Amounts of Gluten. Gastroenterology 2020, 158, 1497-1499. [CrossRef]

20. Stefanolo, J.P.; Tálamo, M.; Dodds, S.; de la Paz Temprano, M.; Costa, A.F.; Moreno, M.L.; Pinto-Sanchez, M.I.; Smecuol, E.; Vasquez, H.; Gonzales, A.; et al. Real-World Gluten Exposure in Patients with Celiac Disease on Gluten-Free Diets, Determined from Gliadin Immunogenic Peptides in Urine and Fecal Samples. Clin. Gastroenterol. Hepatol. 2021. [CrossRef]

21. Bossuyt, P.M.; Reitsma, J.B.; Bruns, D.E.; Gatsonis, C.A.; Glasziou, P.P.; Irwig, L.; Lijmer, J.G.; Moher, D.; Rennie, D.; de Vet, H.C.W.; et al. STARD 2015: An Updated List of Essential Items for Reporting Diagnostic Accuracy Studies. Clin. Chem. 2015, 61, 1446-1452. [CrossRef] [PubMed]

22. Ludvigsson, J.F.; Bai, J.C.; Biagi, F.; Card, T.R.; Ciacci, C.; Ciclitira, P.J.; Green, P.H.R.; Hadjivassiliou, M.; Holdoway, A.; van Heel, D.A.; et al. Diagnosis and management of adult coeliac disease: Guidelines from the British Society of Gastroenterology. Gut 2014, 63, 1210-1228. [CrossRef] [PubMed]

23. Marsh, M.N. Gluten, major histocompatibility complex, and the small intestine. A molecular and immunobiologic approach to the spectrum of gluten sensitivity ('celiac sprue'). Gastroenterology 1992, 102, 330-354. [CrossRef]

24. Oberhuber, G.; Granditsch, G.; Vogelsang, H. The histopathology of coeliac disease: Time for a standardized report scheme for pathologists. Eur. J. Gastroenterol. Hepatol. 1999, 11, 1185-1194. [CrossRef]

25. Casellas, F.; Rodrigo, L.; Molina-Infante, J.; Vivas, S.; Lucendo, A.J.; Rosinach, M.; Duenas, C.; Fernandez-Banares, F.; Lopez-Vivancos, J. Transcultural adaptation and validation of the Celiac Disease Quality of Life (CD-QOL) Survey, a specific questionnaire to measure quality of life in patients with celiac disease. Revista Espanola de Enfermedades Digestivas 2013, 105, 585-593. [CrossRef]

26. Fueyo-Díaz, R.; Gascón-Santos, S.; Asensio-Martínez, Á.; Sánchez-Calavera, M.A.; Magallón-Botaya, R. Transcultural adaptation and validation of the Celiac Dietary Adherence Test. A simple questionnaire to measure adherence to a gluten-free diet. Revista Espanola de Enfermedades Digestivas 2016, 108, 138-144. [CrossRef] 
27. Pinto-Sanchez, M.I.; Bai, J.C. Toward New Paradigms in the Follow Up of Adult Patients with Celiac Disease on a Gluten-Free Diet. Front. Nutr. 2019, 6, 153. [CrossRef]

28. Bai, J.C.; Fried, M.; Corazza, G.R.; Schuppan, D.; Farthing, M.; Catassi, C.; Greco, L.; Cohen, H.; Ciacci, C.; Eliakim, R.; et al. World Gastroenterology Organisation global guidelines on celiac disease. J. Clin. Gastroenterol. 2013, 47, 121-126. [CrossRef]

29. Mooney, P.D.; Evans, K.E.; Singh, S.; Sanders, D.S. Treatment failure in coeliac disease: A practical guide to investigation and treatment of non-responsive and refractory coeliac disease. J. Gastrointest. Liver Dis. 2012, 21, 197-203.

30. Szakács, Z.; Gede, N.; Gyöngyi, Z.; Solymár, M.; Csupor, D.; Erőss, B.; Vincze, A.; Miko, A.; Vasas, A.; Szapary, L.; et al. A Call for Research on the Prognostic Role of Follow-Up Histology in Celiac Disease: A Systematic Review. Front. Physiol. 2019, 10, 1408. [CrossRef]

31. Fang, H.; King, K.S.; Larson, J.J.; Snyder, M.R.; Wu, T.T.; Gandhi, M.J.; Murray, J.A. Undetectable negative tissue transglutaminase IgA antibodies predict mucosal healing in treated coeliac disease patients. Aliment. Pharmacol. Ther. 2017, 46, 681-687. [CrossRef] [PubMed]

32. Tuire, I.; Marja-Leena, L.; Teea, S.; Katri, H.; Jukka, P.; Päivi, S.; Heini, H.; Marrku, M.; Pekka, C.; Katri, K. Persistent duodenal intraepithelial lymphocytosis despite a long-term strict gluten-free diet in celiac disease. Am. J. Gastroenterol. 2012, 107, 1563-1569. [CrossRef] [PubMed]

33. Hære, P.; Høie, O.; Schulz, T.; Schönhardt, I.; Raki, M.; Lundin, K.E.A. Long-Term mucosal recovery and healing in celiac disease is the rule-Not the exception. Scand. J. Gastroenterol. 2016, 51, 1439-1446. [CrossRef] [PubMed]

34. Zanini, B.; Marullo, M.; Villanacci, V.; Salemme, M.; Lanzarotto, F.; Ricci, C.; Lanzini, A. Persistent Intraepithelial Lymphocytosis in Celiac Patients Adhering to Gluten-Free Diet Is Not Abolished Despite a Gluten Contamination Elimination Diet. Nutrients 2016, 8, 525. [CrossRef] [PubMed]

35. Van Meensel, B.; Hiele, M.; Hoffman, I.; Vermeire, S.; Rutgeerts, P.; Geboes, K.; Bossuyt, X. Diagnostic accuracy of ten secondgeneration (human) tissue transglutaminase antibody assays in celiac disease. Clin. Chem. 2004, 50, 2125-2135. [CrossRef] [PubMed]

36. Sugai, E.; Nachman, F.; Váquez, H.; González, A.; Andrenacci, P.; Czech, A.; Niveloni, S.; Mazure, R.; Smecuol, E.; Cabanne, A.; et al. Dynamics of celiac disease-specific serology after initiation of a gluten-free diet and use in the assessment of compliance with treatment. Dig. Liver Dis. 2010, 42, 352-358. [CrossRef]

37. Laserna-Mendieta, E.J.; Pineda-Tenor, D.; Timón-Zapata, J.; Carretero-Gómez, J.F.; Valle-Muñoz, J.; Gómez-Serranillos, M. A proposed reference change value for an $\operatorname{IgA}$ anti-tissue transglutaminase immunoassay to improve interpretation of serial results in celiac patients. Clin. Chim. Acta 2013, 421, 12-16. [CrossRef]

38. Nachman, F.; Sugai, E.; Vázquez, H.; González, A.; Andrenacci, P.; Niveloni, S.; Mazure, R.; Smecuol, E.; Moreno, M.L.; Hwang, H.J.; et al. Serological tests for celiac disease as indicators of long-term compliance with the gluten-free diet. Eur. J. Gastroenterol. Hepatol. 2011, 23, 473-480. [CrossRef]

39. Ruiz-Carnicer, Á.; Garzón-Benavides, M.; Fombuena, B.; Segura, V.; García-Fernández, F.; Sobrino-Rodríguez, S.; Gomez-Isquierdo, L.; Montes-Cano, M.A.; Rodriguez-Herrera, A.; Millan, R.; et al. Negative predictive value of the repeated absence of gluten immunogenic peptides in the urine of treated celiac patients in predicting mucosal healing: New proposals for follow-up in celiac disease. Am. J. Clin. Nutr. 2020, 112, 1240-1251. [CrossRef]

40. Porcelli, B.; Ferretti, F.; Cinci, F.; Biviano, I.; Santini, A.; Grande, E.; Quagliarella, F.; Terzuoli, L.; Bacarelli, M.R.; Bizzaro, N.; et al. Fecal gluten immunogenic peptides as indicators of dietary compliance in celiac patients. Minerva Gastroenterologica e Dietologica 2020, 66, 201-207. [CrossRef]

41. Akobeng, A.K.; Thomas, A.G. Systematic review: Tolerable amount of gluten for people with coeliac disease. Aliment. Pharmacol. Ther. 2008, 27, 1044-1052. [CrossRef] [PubMed]

42. Porcelli, B.; Ferretti, F.; Biviano, I.; Santini, A.; Cinci, F.; Vascotto, M.; Grande, E.; Quagliarella, F.; Terzuoli, L.; Bizzaro, N.; et al. Testing for fecal gluten immunogenic peptides: A useful tool to evaluate compliance with gluten-free diet by celiacs. Ann. Gastroenterol. 2020, 33, 631-637. [CrossRef] [PubMed] 